\title{
Nitric Oxide Levels of Turbulent Jet Diffusion Flames: Effects of Residence Time and Damkohler Number
}

\author{
JAMES F. DRISCOLL, RUEY-HUNG CHEN, * and YOUNGBIN YOON \\ Department of Aerospace Engineering, The University of Michigan, Ann Arbor, MI 48109-2140
}

\begin{abstract}
The global residence time and the deviations from chemical equilibrium (i.e., the Damkohler number) were varied for a number of jet diffusion flames. The resulting effects on the nitric oxide emission index were measured and were compared with existing analysis. The global residence time is defined as $L_{f} / U_{F}$, where $L_{f}$ is the flame length and $U_{F}$ is the fuel jet velocity. Flame length is varied by increasing the jet diameter, by adding either premixed air or inerts to the fuel jet, or by adding a coaxial air stream. In particular, a unique jet flame was studied that is composed of helium-diluted hydrogen fuel; this flame is free of the complicating effects of flame radiation, buoyancy, and prompt NO and provides a useful baseline comparison to theory. It is found that $\mathrm{NO}_{x}$ levels for three types of fuels were consistently less than levels predicted by thermal theory, which suggests that one or both of the two mechanisms that suppress $\mathrm{NO}_{x}$, namely strain and radiative cooling, are important. The use of a Damkohler number was found to successfully correlate the $\mathrm{NO}_{x}$ data for the hydrogen/helium-air flames that have simple chemistry. As the helium concentration is increased in order to reduce the Damkohler number, the measured $\mathrm{NO}_{x}$ emission index exceeds that of the equilibrium theory by as much as a factor of 24 , which is further indication that it is important to add the correct nonequilibrium oxygen atom chemistry to current models.
\end{abstract}

\section{INTRODUCTION}

Peters and Donnerhack [1] have developed a theory that predicts that the emission index of nitric oxides associated with a nonpremixed turbulent jet flame should be proportional to the global residence time $L_{f} / U_{F}$. However, experimental trends reported to date [2-6] deviate from this thermal theory. The deviations are believed to be due to the existence of additional $\mathrm{NO}_{x}$ producing mechanisms that are not included in the thermal $\mathrm{NO}_{x}$ theory. Four mechanisms that experimentally have been proven to affect $\mathrm{NO}_{x}$ in certain flames are (a) aerodynamic strain [7], (b) radiative cooling $[3,4]$, (c) superequilibrium oxygen chemistry [5, 8-10], and (d) prompt NO chemistry [11]. The first two mechanisms reduce the $\mathrm{NO}_{x}$ levels below that predicted by thermal theory, while the latter two mechanisms increase the $\mathrm{NO}_{x}$ levels above that predicted by the thermal theory. Drake and Blint [7] showed that increasing the strain rate on a laminar counterflow flame reduces the gas temperature and the thermal NO levels. Chen and Driscoll [2] re-

\footnotetext{
* Present address: Department of Mechanical and Aerospace Engineering, Princeton University, Princeton, NJ 08544.
}

ported some effects of strain on turbulent jet flames. Turns and Lovett [3] and Turns and Myhr [4] studied sooty propane and ethylene flames and showed that radiative heat losses are sufficient to reduce NO production in some cases. However, if a cleaner fuel or coaxial air is used or if the jet velocity is increased, the effects of radiative losses can be substantially less than that reported by Turns and Lovett [3]. In many flames, the four mechanisms described above exist simultaneously, which can make it impossible to correlate $\mathrm{NO}_{x}$ data with any single strain or radiation parameter.

Because of the above complications, it was decided to study hydrogen-air flames and in particular, to study helium-diluted hydrogen-air flames because radiative cooling, prompt NO, and buoyancy effects can be eliminated in such flames. Furthermore, the deviations from chemical equilibrium were maximized by using a $30 \%$ hydrogen-70\% helium fuel at high strain rates in order to assess superequilibrium oxygen effects. In other cases, deviations from equilibrium were minimized by using pure hydrogen fuel at lower strain rates. Flame length was decreased by either decreasing the jet diameter, by adding coaxial (nonpremixed) air to the jet, or by directly adding premixed air or inerts into the fuel jet. In all 
cases only a jet flame geometry was considered; neither swirl nor a bluff-body stabilizer was used. One motivation for the measurements is to assist in the development of new $\mathrm{NO}_{x}$ prediction models $[10,12,13]$ which offer the only possibility of explaining $\mathrm{NO}_{x}$ measurements if the four mechanisms (a-d) listed above are present simultaneously. The models, along with the present type of measurements, are needed to determine how $\mathrm{NO}_{x}$ scales with residence time so that trends measured in laboratory combustors can be applied to larger scale devices.

The thermal $\mathrm{NO}_{x}$ analysis of Peters [1] considers the simplest possible case and neglects the effects of strain, radiation superequilibrium oxygen chemistry, and prompt NO. For these conditions, the $\mathrm{NO}_{x}$ emission index (EINOX) for a turbulent jet flame is defined to be the total grams of $\mathrm{NO}_{x}$ formed per kilogram of fuel and is predicted to be equal to

$\operatorname{EINOX}=0.057\left(L_{f}^{3} /\left(d^{* 2} U_{F}\right)\right)\left(S_{\mathrm{NO}, b} \epsilon \rho_{\mathrm{ST}} / \rho_{A}\right)$.

$S_{\mathrm{NO}, b}$ and $\epsilon$ are constants that depend on the known thermal NO kinetics, the equilibrium gas concentrations, and the gas temperature, as determined by the NASA CEC code. Values of $S_{\mathrm{No}, b}$ and $\epsilon$ are given in Ref. 1 . The effective jet diameter $d^{*}$ is $m /\left(\pi \rho_{A} J / 4\right)^{1 / 2}$, where $m$ is the jet mass flowrate (including fuel, inerts and premixed or coaxial air, if present) and $J$ is the jet momentum flux $[14,15]$. If the jet consists of fuel only, then $m$ is $\rho_{F} U_{F} d_{F}^{2} / 4, J$ is $\rho_{F} U_{F}^{2} d_{F}^{2} / 4$, and $d^{*}$ equals $d_{F}\left(\rho_{F} / \rho_{A}\right)^{1 / 2}$, where $d_{F}$ is the jet tube diameter. Air density is $\rho_{A}$ and the density of the stoichiometric mixture is $\rho_{\mathrm{ST}}$.

In order to explain the present data, it is necessary to describe Eq. 1 in a physical sense. Consider the instantaneous flame location as well as the conserved scalar contours that correspond to a temperature of $1700 \mathrm{~K}$. One such contour lies on the lean side of the flame and the other lies at the rich side. The quantity $d(\mathrm{NO}) / d t$ is negligible in the zone outside of the reaction region defined by these contours, and equals $2 k(\mathrm{O})\left(\mathrm{N}_{2}\right)$ inside the reaction region if mechanisms other than thermal NO production are neglected [5]. For a jet geometry, the mean conserved scalar profiles are known and Peters uses equilibrium chemistry assump- tions to relate $(\mathrm{O}),\left(\mathrm{N}_{2}\right)$, and $\mathrm{T}$ to the conserved scalar. Equation 1 is derived by calculating $M_{\mathrm{NO}} d(\mathrm{NO}) / d t$, which is the grams NO produced per second per unit volume, and then integrating this quantity over the reaction volume to yield the total grams NO produced per second by the flame.

Since the time-averaged conserved scalar profiles are assumed to be self-similar in Peters' theory, it is expected that the reaction zone volume should scale with the cube of the flame length $\left(L_{f}^{3}\right)$; in fact, this factor does appear in Eq. 1. Thus EINOX is predicted to scale linearly with reaction zone volume. Since flame length $L_{f}$ is proportional to $d^{*}[1]$, when the jet consists of pure fuel only, Eq. 1 can be simplified to

$\mathrm{EINOX}=1.62\left(L_{f} / U_{F}\right)\left(S_{\mathrm{NO}, b} \epsilon / Z_{s}^{2}\right)$.

The quality $Z_{s}$ is the stoichiometric mixture fraction. Equation 2 shows that thermal EINOX is predicted to scale with global residence time $\left(L_{f} / U_{F}\right)$. The actual residence time for NO production depends on the local thickness of the thin, wrinkled (and strained) reaction layers and the local gas velocity; however, for the self-similar conditions assumed by the theory, the local residence time is predicted to be proportional to the global residence time.

Improved $\mathrm{NO}_{x}$ models that include strain, complex chemistry, and flame radiation are being developed by Dahm et al. [13], Lutz et al. [12], and Chen and Kollmann [10]. For example, strain can significantly change the reaction layer thickness and thus change the actual residence time. Carrier et al. [16] show that the reaction layer thickness of a strained laminar nonpremixed flame scales as $\sqrt{D / \epsilon} D a^{n}$, where $D$ is the gas diffusivity, $\epsilon$ is the strain rate, $\mathrm{Da}$ is the Damkohler number $\left[\left(S_{L}{ }^{2} / \alpha\right) /\left(U_{F} / d_{F}\right)\right]$, which also depends on strain rate, and $n$ is determined by the order of the chemical reaction and is typically $0.4 . S_{L}$ is the stoichiometric laminar burning velocity and $\alpha$ is the thermal diffusivity.

Another factor that can cause measurements to deviate from Eq. 1 is local premixing of fuel and air. This factor is addressed in the present work by specifically adding various amounts of air to the fuel jet. Equation 1 predicts that EINOX can be reduced by forcing air into the flame, thereby reducing flame length $L_{f}$. This trend is measured 
herein, but is not expected to continue indefinitely. As the residence time is reduced by adding forced air, the flame becomes short, intense, and exists where the local jet velocity and turbulence levels are relatively large. In such flames the local premixing is expected to favor $\mathrm{NO}_{x}$ production and prevent further $\mathrm{NO}_{x}$ reduction. Bilger [17] and others have identified local premixing and deviations from strained diffusion layer theory as an important factor in $\mathrm{NO}_{x}$ production.

\section{EXPERIMENTAL ARRANGEMENT}

Each of the jet flames was operated in a coflowing air stream, shown in Fig. 1. The coflow air was used in order to dilute the combustion products with a known air flow rate in order to accurately determine the $\mathrm{NO}_{x}$ emission index (grams $\mathrm{NO}_{x} / \mathrm{kg}$ fuel) from the measured $\mathrm{NO}_{x}$ concentration (in ppm) far downstream of the flame. The coflow air velocity in all cases was less than $3 \%$ of the fuel exit velocity. The coflow air first passed through honeycombs and screens and a tapered inlet having a contraction area ratio of 2.8 and then through a $15-\mathrm{cm}$-diameter steel

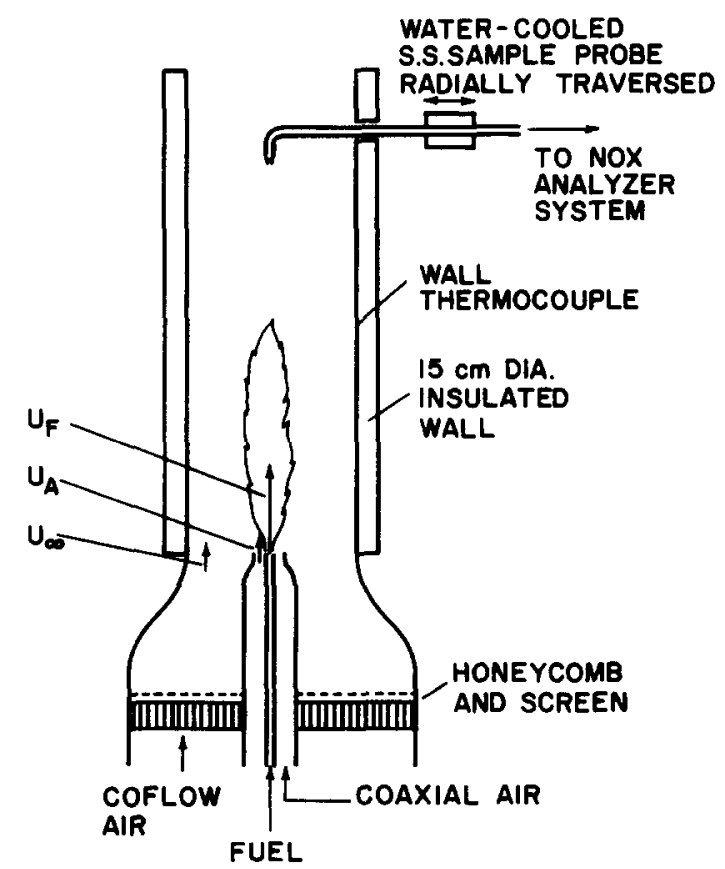

Fig. 1. Apparatus for the $\mathrm{NO}_{x}$ emission index measurement. Note the difference between coaxial air, which contributes to the jet momentum, and coflow air, which does not contribute. tube $2 \mathrm{~m}$ long that surrounded the flame. The coflowing air velocity was found to be sufficiently small so as not to affect $\mathrm{NO}_{x}$ levels or flame lengths, as shown below. In some cases, coaxial air also was used. Coaxial air is defined as air that in the present case passed through an air tube of diameter $0.87 \mathrm{~cm}$ that is concentric with the fuel tube. The coaxial air momentum is considered to be part of the jet itself and has a large effect on the $\mathrm{NO}_{x}$ levels, which are described below. No swirl was used. The inlet temperature of fuel and air was $294 \mathrm{~K}$ and the wall temperature was typically less than $300^{\circ} \mathrm{C}$, which is sufficiently low so that wall radiation effects can be neglected.

$\mathrm{NO}$ and $\mathrm{NO}_{2}$ were measured using a hotwater-cooled stainless-steel sampling probe that always was located at least two flame lengths from the jet exit. The 2.8-mm-diameter probe was cooled with water at $50^{\circ} \mathrm{C}$ which provided probe temperatures low enough to quench $\mathrm{NO}_{x}$ reactions yet large enough to prevent condensation of water vapor. Drake et al. [5] has shown that for probe locations exceeding two flame lengths from the jet exit, four different types of probes yield identical results. The sampled gas passed through an ice bath $/ \mathrm{H}_{2} \mathrm{O}$ trap, a thermal converter, and a Scott 125 chemiluminescence NO detector.

To determine the $\mathrm{NO}_{x}$ emission index, it first was determined that the $\mathrm{NO}$ and $\mathrm{NO}_{2}$ concentration values (in ppm) were constant in the radial direction to within $\pm 3 \%$, which indicates that well-mixed conditions occur at the probe location -at two flame lengths downstream of the jet exit. Therefore it is not necessary to measure the radial profiles of $\mathrm{NO}_{x}$, temperature, or velocity. For a hydrogen-air flame, NO emission index is determined using:

$$
\begin{aligned}
\text { EINO }= & 0.001\left(M_{\mathrm{NO}} / M_{\mathrm{H}_{2}}\right) \\
& \times \chi_{\mathrm{NO}}\left(\left(1+\left(4.76 / \phi_{0}\right)\right) / 2,\right.
\end{aligned}
$$

where $\chi_{\text {NO }}$ is the measured centerline NO concentration in parts per million and $M$ denotes molecular weight. The equivalence ratio $\phi_{0}$ is based on the total fuel and air flowrates and is a measure of the degree of dilution of the products; $\phi_{0}$ varies from 0.25 to 0.5 . Equation 3 is derived 
by writing

$$
\begin{aligned}
\mathrm{H}_{2} & +\frac{1}{2 \phi_{0}} \mathrm{O}_{2}+\frac{1}{2 \phi_{0}} \frac{79}{21} \mathrm{~N}_{2} \rightarrow \mathrm{H}_{2} \mathrm{O} \\
& +\left(\frac{1}{2 \phi_{0}}-\frac{1}{2}\right) \mathrm{O}_{2}+\frac{1}{2 \phi_{0}} \frac{79}{21} \mathrm{~N}_{2}+a \mathrm{NO}
\end{aligned}
$$

where $a$ represents moles $\mathrm{NO}$ per mole $\mathrm{H}_{2}$. The NO emission index EINO, in grams NO per kilogram fuel, is $1000\left(M_{\mathrm{NO}} / M_{\mathrm{H}_{2}}\right) a$. The quantity $a$ is eliminated by noting that for the above stoichiometry the number of moles of NO divided by the total number of moles of product is $a /\left[(1 / 2)\left(1+4.76 / \phi_{0}\right)\right]$; equating this quantity to the measured concentration $\chi_{\mathrm{NO}}$ (in ppm) multiplied by $10^{-6}$ yields Eq. 3. To determine EINOX, Eq. 3 is used with $\chi_{\text {NO }}$ replaced with $\chi_{\mathrm{NO}_{x}}$ and $M_{\mathrm{NO}}$ is replaced with $M_{\mathrm{NO}_{2}}$. The molecular weight of $\mathrm{NO}_{2}$ is conventionally used in the standard definition of EINOX because nearly all of the grams of NO eventually are converted to grams of $\mathrm{NO}_{2}$ in the atmosphere [18]. The coflow air velocity $\left(U_{\infty}\right)$ is proportional to $1 / \phi_{0}$; it is shown below that the coflow air velocities chosen were small enough such that variations of $U_{\infty}$ (or $\phi_{0}$ ) do not affect the $\mathrm{NO}_{x}$ emission index. It also was verified that EINOX does not vary in the axial direction at locations exceeding $2 L_{f}$. For example, EINOX for a methane-air jet flame $\left(\operatorname{Re}=6000, \phi_{0}=0.5\right)$ varied by less than $4.5 \%$ as the probe location was varied from $x=1.8 L_{f}$ to $x=3.2 L_{f}$.

\section{RESULTS}

Some values of $\mathrm{NO}_{x}$ emission index for hydrogen-air, methane-air, and propane-air flames are presented in Fig. 2. The hydrogen-air flame results in Fig. 2 were reported previously [2] but are included to provide comparison to diluted and premixed flames, which are discussed below. For hydrogen and methane fuel the curves display a negative slope in the turbulent regime $(\operatorname{Re}>$ 4000) which indicates that as jet velocity $U_{F}$ increases, EINOX decreases. This trend is consistent with $\mathrm{Eq} .1$ and the concept that increasing jet velocity reduces the residence time. Figure 2 also shows that reducing the jet diameter $d_{F}$, which reduces flame length, also reduces EINOX, in agreement with Eq. 1 .

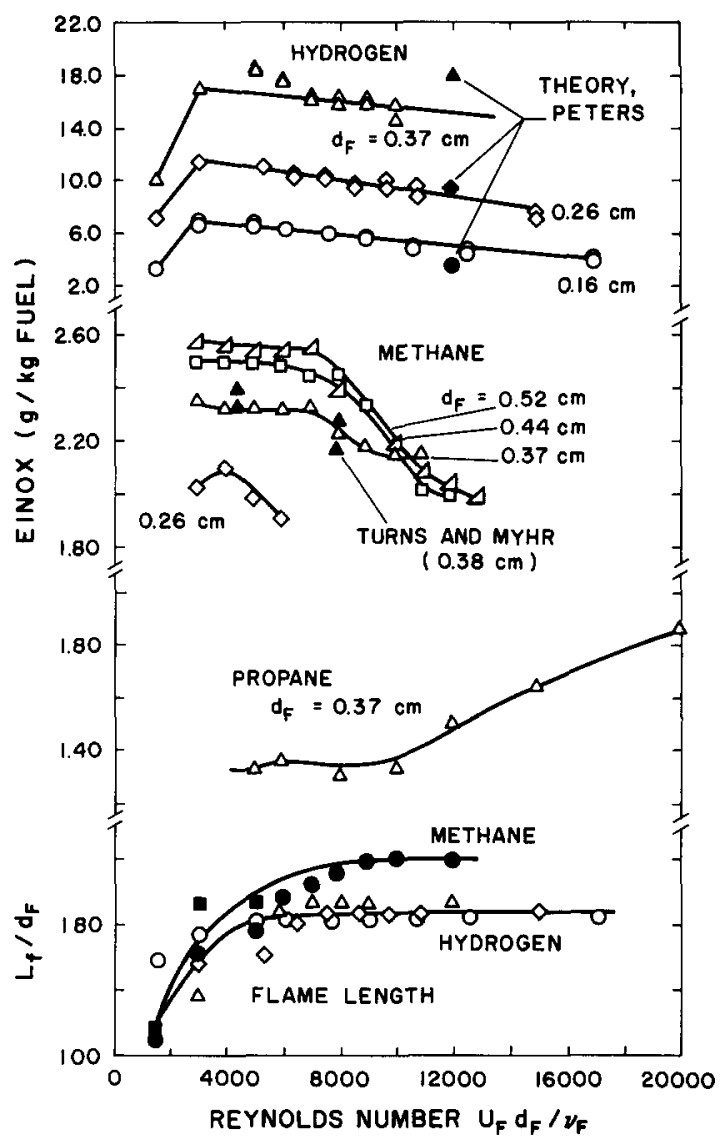

Fig. 2. $\mathrm{NO}_{x}$ emission index results for hydrogen, methane, and propane jet flames. For each curve only the jet velocity is varied. Also shown is measured flame length.

Some theoretical values of EINOX were calculated using Eq. 1 and are compared with the hydrogen flame data in Fig. 2. For the hydrogen-air flame at $\operatorname{Re}=12,000$, the agreement is seen to be good. However, for methane-air and propane-air flames, the measured values are two to the three times less than values predicted by Eq. 1. For example, for a methane-air flame at $\operatorname{Re}=11,000$ and $d_{F}=0.37 \mathrm{~cm}$, the calculated value of EINOX is $3.8 \mathrm{~g} / \mathrm{kg}$ while the measured value is $2.15 \mathrm{~g} / \mathrm{kg}$. Similarly, for a propane-air flame at $\operatorname{Re}=12,000$ and $d_{F}=0.37 \mathrm{~cm}$, the calculated value of EINOX is $4.21 \mathrm{~g} / \mathrm{kg}$ while the measured value is $1.69 \mathrm{~g} / \mathrm{kg}$. Therefore all of the present $\mathrm{NO}_{x}$ measurements for methane, propane, and undiluted hydrogen flames are less than (or equal to) the thermal theory values. This difference cannot be explained by prompt NO or superequilibrium oxygen effects, since both ef- 
fects, if added to the calculation, would increase the calculated values and thus amplify the differences noted in Fig. 2. Instead, the observation that actual $\mathrm{NO}_{x}$ levels are lower than the theory indicates that a mechanism is present that suppresses $\mathrm{NO}_{x}$ formation, such as strain and/or radiation losses.

To assess if the differences between theory and measurements in Fig. 2 are due to possible experimental errors, some $\mathrm{NO}_{x}$ values measured by Turns and Myhr [4] are plotted in Fig. 2. Turns and Myhr used the same fuel, the same jet diameters and jet velocities as were used for one of the curves in Fig. 2. However, they used no coflow air; instead of directly measuring the dilution air flowrate that is required in Eq. 2 to deduce EINOX, they inferred the dilution air flowrate by measuring the $\mathrm{CO}_{2}$ concentration far downstream of the flame. Figure 2 shows that the Turns and Myhr data and the present data agree reasonably well for the one case for which operating conditions are identical.

It is noted that when propane fuel is used, the resulting curve in Fig. 2 has a positive slope, which is consistent with results of Turns and Lovett [3] and is attributed to radiation effects. That is, increasing the jet velocity $U_{F}$ decreases the radiant energy loss fraction, which scales as
$\left(L_{f}^{3} / U_{F} d_{F}{ }^{2}\right) \epsilon_{s} T^{4}[3,4,19]$, where $\epsilon_{s}$ is the effective emissivity of the soot particles. In proceeding to the right along the curve in Fig. 2, it was observed that the color of the propane-air flame changes from yellow to blue, which is consistent with the idea that the decreased radiant loss fraction tends to increase flame temperature and tends to cause the observed positive slope in Fig. 2. It also is noted that in the laminar flame regime $(\operatorname{Re}<4000)$ the curves in Fig. 2 have a positive slope; this trend also is explained by Eq. 1. In the laminar flame regime, the term $\left(L_{f} / d^{*}\right)^{2}$ in Eq. 1 is not constant; instead flame length is proportional to jet velocity so this term is proportional to $U_{F}^{2}$ and EINOX in Eq. 1 is proportional to $U_{f}$, which causes the observed positive slope.

Equation 1 predicts that thermal EINOX data should collapse to a single, horizontal line if the results are plotted using the vertical coordinates used in Fig. 3. It is found that the thermal $\mathrm{NO}_{x}$ results (i.e., the hydrogen-air flame data) for a wide range of velocities and jet diameters do collapse to a single line but the slope of the line in Fig. 3 is 0.5 . By observing the trends in Fig. 2, it was found that it is necessary to use the parameter $U_{F} / d_{F}$ as the abscissa in Fig. 3 in order to collapse the thermal $\mathrm{NO}_{x}$ data to a single curve.

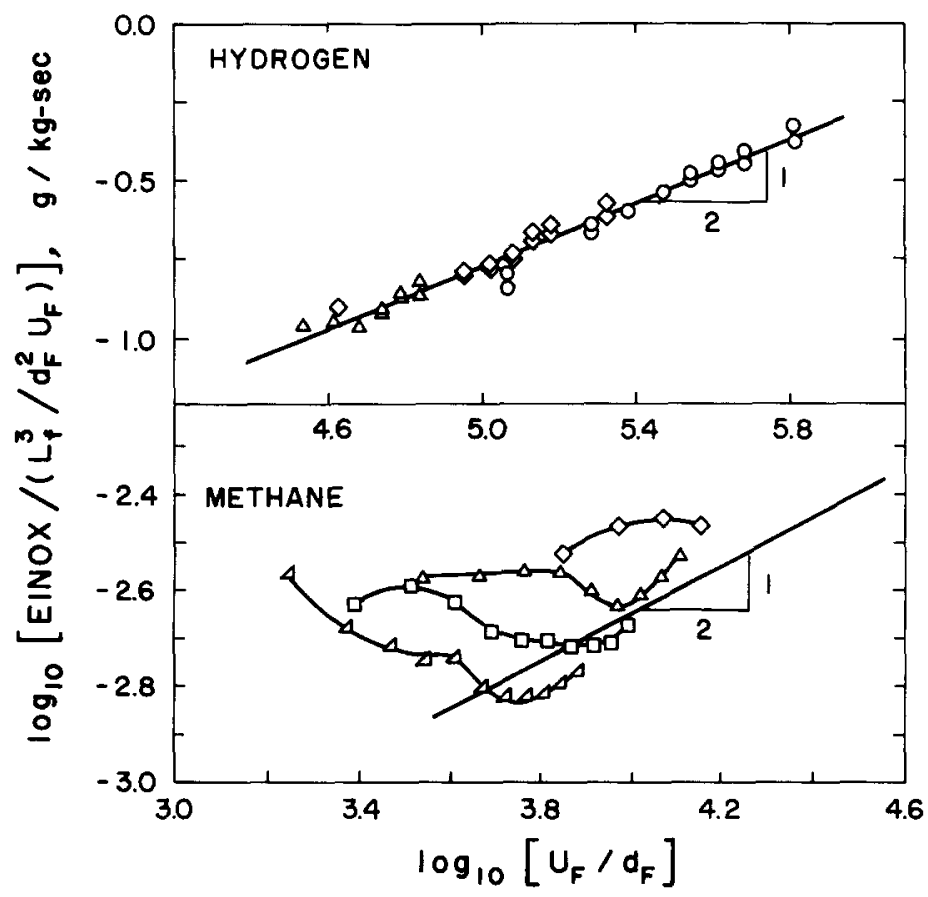

Fig. 3. $\mathrm{NO}_{x}$ emission index normalized by parameters in Peters' theory showing that thermal $\mathrm{NO}_{x}$ (i.e., hydrogen-air flame) data collapse to a single line if the parameter $\left(U_{f} / d_{F}\right)$ is used. $d_{f}=\odot, 0.16 \mathrm{~cm} ; \diamond, 0.26$ $\mathrm{cm} ; \triangle, 0.37 \mathrm{~cm} ; \square, 0.44 \mathrm{~cm} ; \triangleright, 0.52 \mathrm{~cm}$. 
If the Reynolds number or Froude number is used instead as the abscissa, the data do not collapse to a single curve, indicating that Reynolds number or Froude number is not the relevant parameter. Previous attempts to correlate $\mathrm{NO}_{x}$ data using Froude number have shown that the Froude number dependence of the data does not approach zero as Froude number approaches infinity, which is contrary to physical intuition.

The observation that the parameter $U_{F} / d_{F}$ collapses the hydrogen-air data to a single curve indicates that the Damkohler number is an important governing parameter. $U_{F} / d_{F}$ can be interpreted either as a strain rate, an inverse residence time or as a mixing rate, which, when normalized by the heat release reaction rate $\left(S_{L}{ }^{2} / \alpha\right)$, is the inverse Damkohler number. The strain and the superequilibrium oxygen chemistry mechanisms are related and are controlled by the Damkohler number, since strain causes deviations from equilibrium [16]. Therefore, the trends shown in Fig. 3 are most likely due to both strain and nonequilibrium chemistry. The complexity that is added by the nonequilibrium chemistry is discussed by Drake and Blint [7]. Strain, in the absence of nonequilibrium chemistry, tends to reduce flame temperature and reaction zone width [16]. However, when strain causes deviations from equilibrium, the $\mathrm{NO}_{x}$ reaction zone instead can be broadened since $\mathrm{NO}_{x}$ production is enhanced at the rich and lean edges of the reaction zone $[5,7]$.

A hydrogen jet flame that is similar to the one studied herein was modeled by Chen and Kollmann [10], who calculated two trends that agree with Fig. 3. Their calculations showed that $\mathrm{NO}_{x}$ emission index values collapse to a single line when the parameter $U_{F} / d_{F}$ is used, and that the slope of this line is 0.5 , in agreement with Fig. 3 . They attribute these trends to the nonequilibrium chemistry that was included in their model. In contrast to the hydrogen flame data, the methane flame data in Fig. 3 do not collapse to a single curve but appear to approach a single curve having a positive slope at sufficiently large jet velocity. Because of complex chemistry and/or soot radiation effects, it is not surprising that the scaling parameters suggested by a simple analysis do not correlate with the methane-air data.

The effect of buoyancy on the flames in Figs. 2 and 3 was determined by calculating the local
Richardson number parameter defined as $\xi_{L}$ by Becker and Liang [20]. Becker defines $\xi_{L}$ as $\left(g \rho_{A} L_{f}^{2} /\left(\rho_{F} U_{F}^{2} d_{F}^{2}\right)\right)^{1 / 3}$ and finds that his vertical jet flames and those of Hawthorne et al. [21] lie in the forced convection range (i.e., have lengths that are independent of Richardson number) if $\xi_{L}$ is less than 5. All of the present hydrogen-air flames having jet Reynolds numbers $\left(\operatorname{Re}_{F}\right)$ exceeding 4000 are found to have $\xi_{L}$ less than 5 and are found to have measured flame lengths that are independent of fuel velocity, as shown in Fig. 2, and can be considered to be free from buoyancy effects. The methane-air flames experience a $10 \%$ variation in flame length due to buoyancy. However, this small variation is taken into account by using the measured flame length in Eqs. 1 and 2 and when computing the normalized EINOX values in Fig. 3. Therefore, the trends observed in Fig. 3 are not believed to be affected by the $10 \%$ variations in flame length due to buoyancy. For the diluted flames discussed below, the flame lengths are significantly reduced by adding inerts or air to the jet so that $\xi_{L}$ is significantly less than 5 and buoyancy effects are negligible.

\section{VARYING THE EFFECTS OF SUPEREQUILIBRIUM OXYGEN BY ADDING HELIUM}

One way to assess complex chemistry models of NO formation is to add an inert such as helium that depresses the flame temperature but does not itself take part in the reaction. Complex chemistry models $[5,10]$ predict that the addition of an inert reduces flame temperature, which tends to reduce the NO formation rate; however, this reduction is partially offset by the superequilibrium oxygen mechanism. That is, as the inerts reduce the reaction rate and the Damkohler number, the deviation from chemical equilibrium increases and the kinetics favor the formation of superequilibrium $\mathrm{OH}$ and $\mathrm{O}$ levels that can be two orders of magnitude greater than equilibrium levels. Damkohler number for the jet is defined as $\left(S_{L}{ }^{2} / \alpha\right) /\left(U_{F} / d^{*}\right)$, where $S_{L}$ is the laminar burning velocity and $\alpha$ is the thermal diffusivity.

Figure 4 shows how $\mathrm{NO}_{x}$ emission index is affected by the addition of helium to the hydrogen fuel in order to vary the Damkohler number. The theory of Peters and Donnerhack [1] is also shown 


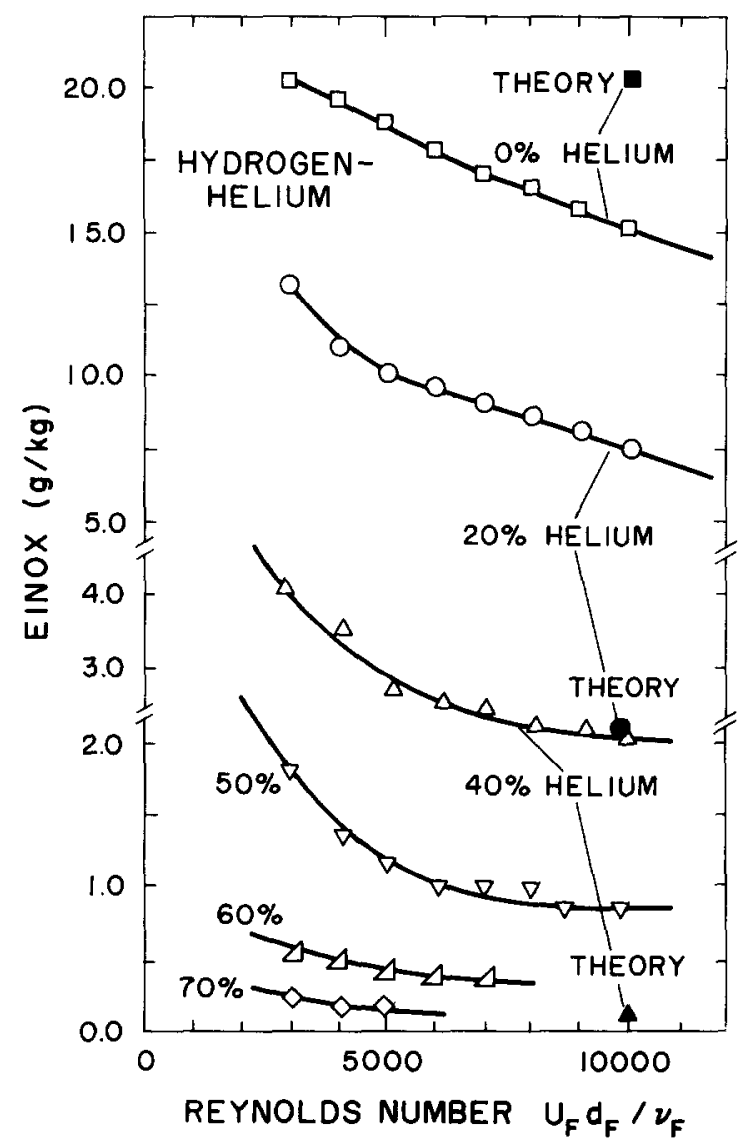

Fig. 4. Effect of adding helium inert to a hydrogen-air jet flame. For $40 \%$ or larger helium dilution, flame radiant fraction is negligible and is estimated to equal 0.001. $d_{\digamma}=$ $0.37 \mathrm{~cm}$.

for three cases represented by solid symbols that were calculated using Eq. 1. The NO reaction rate factor $S_{\mathrm{NO}}$ in Eq. 1 is reduced by the helium addition since $S_{\mathrm{NO}}$ depends on the adiabatic flame temperature. The factor $L_{f}{ }^{3}$ in Eq. 1 is also reduced by the helium additions. The value of the flame length $\left(L_{f}\right)$ used in Eq. 1 was measured and is reported in Fig. 5.

The major observation deduced from Fig. 4 is that with helium addition (i.e., reduced Damkohler number), the measured $\mathrm{NO}_{x}$ emission index significantly exceeds the values predicted by the equilibrium theory, which indicates that large deviations from equilibrium occur for the present flames. With $40 \%$ helium, measured EINOX is 24 times larger than the predicted EINOX. It is noted that mechanisms other than nonequilibrium chemistry are not likely to be responsible for the trends observed in Fig. 4.
Aerodynamic strain acts in a direction opposite to the trends observed in Fig. 4; strain tends to cause measured EINOX to be less than theoretical values.

It also is noted that the present hydrogenhelium flames are especially useful for comparison with complex chemistry models because when $40 \%$ helium or more is used, the present flames have essentially no radiation, buoyancy, or prompt NO mechanisms to affect the NO production rate. Figure 5 shows that the helium significantly reduces flame length, which decreases the Richardson number and radiant heat loss fraction, as discussed below. The error in measuring the flame length consisted of two contributions; the random day-to-day variation was less than $\pm 15 \%$, but this was reduced to $\pm 7 \%$ by averaging over four observations. A consistent error (which does not vary from day to day) is due to the definition of the visible flame tip, which in the present case is the location where visible radiation occurs approximately $50 \%$ of the time. Hawthorne et al. [21] used a different criterion and their empirical theory predicts values that are $17 \%$ less, but follow the same trends as the present measurements. The consistent errors between flame lengths reported by various researchers will not affect the trends in the normalized $\mathrm{NO}_{x}$ data (i.e., Fig. 3) but will affect the absolute values.

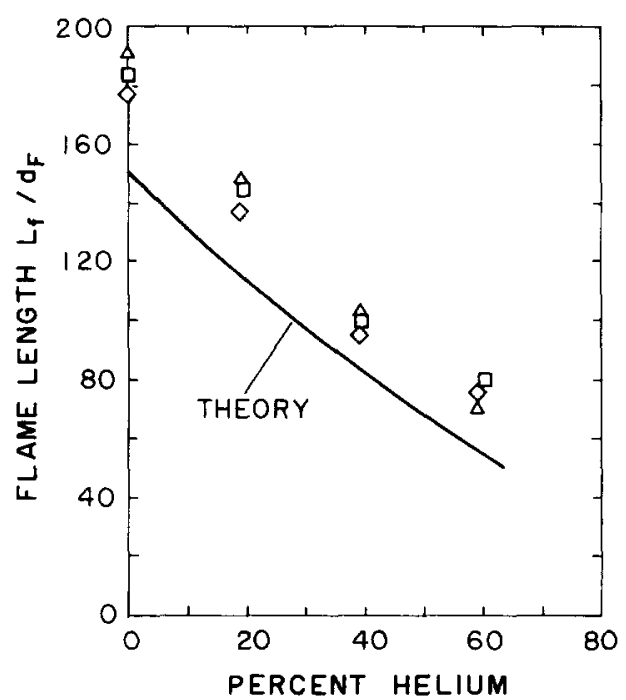

Fig. 5. Effect of helium addition on the length of a hydrogen helium-air jet flame. $\operatorname{Re}=7000 ; d_{F}=\triangle, 0.37 \mathrm{~cm} ; \square, 0.44$ $\mathrm{cm} ; \triangleright, 0.52 \mathrm{~cm}$. Also shown is theory of Hawthorne et al. [21]. 
The helium shortens the flame because it has twice the molecular weight of hydrogen so that it increases the jet momentum and the air entrainment rate. The diluted jet fluid also requires less entrained air to consume the fuel than does a pure fuel jet. The Richardson number parameter $\xi_{L}$ defined above is less than 5 for all of the hydrogen-helium flames studied so buoyancy effects can be neglected [20]. The radiant heat loss fraction for the present hydrogen-helium flames can be estimated to be $A\left(L_{f}^{3} / U_{F} d_{F}{ }^{2}\right) T^{4}$ [19], where $A$ is $5.4 \times 10^{-17} \mathrm{~K}^{-4} \mathrm{~s}^{-1}$, which was measured [4] for a soot-free hydrogen-CO flame having radiation properties similar to a hydrogen jet flame [22]. Therefore for a jet Reynolds number of 9000 and $d_{F}=0.37 \mathrm{~cm}$, the radiant fraction of a pure hydrogen flame is 0.08 ; for the same Reynolds number, a $40 \% \mathrm{H}_{2} / 60 \%$ He flame has an estimated radiant fraction of 0.001 , which is a reduction of nearly two orders of magnitude due to the reduced flame temperature and flame length. The diffusivity of helium into air is $0.72 \mathrm{~cm}^{2} / \mathrm{s}$ at $300 \mathrm{~K}$ and is nearly equal to that of hydrogen into air $\left(0.77 \mathrm{~cm}^{2} / \mathrm{s}\right.$ at $\left.300 \mathrm{~K}\right)$ so it is believed that the helium addition should not cause additional preferential diffusion effects.

Since consistent trends were observed previously for pure hydrogen flames when EINOX was normalized by residence time (Fig. 3), it was decided to compare normalized EINOX data for the helium-diluted flames with the undiluted case. Figure 6 shows the encouraging result that the normalized data for each helium-diluted flame has a slope of 0.5 , which is the same slope that is observed in Fig. 3 for a series of pure hydrogen jet flames. In order to compare jet flames having different jet fluids, the effective jet diameter $d^{*}$, as defined previously, was used [14, 15].

\section{VARYING RESIDENCE TIME BY ADDING PREMIXED AIR}

The global residence time was varied by shortening the jet flame by adding premixed air to the jet. Premixed air is defined as air that has been mixed with the fuel inside the fuel tube. Less than a stoichiometric amount of premixed air is used, so the surrounding coflow air is also required to complete combustion. The premixed air has two effects; it reduces flame length and residence time and it could change the structure of the reaction zone. It was decided to compare two jet flames - one that is downstream of a single tube in which fuel and air are premixed, and one that is downstream of two concentric tubes with the outer tube providing pure air and the inner tube providing pure fuel. Both flames have the same total fuel and air flowrates and the same normalized flame length, as shown below; only the initial degree of fuel-air premixing differs. The resulting $\mathrm{NO}_{x}$ measurements are needed to assess models that can account for different degrees of mixing (by including "homogeneously mixed zones" as well as strained laminar flamelets).

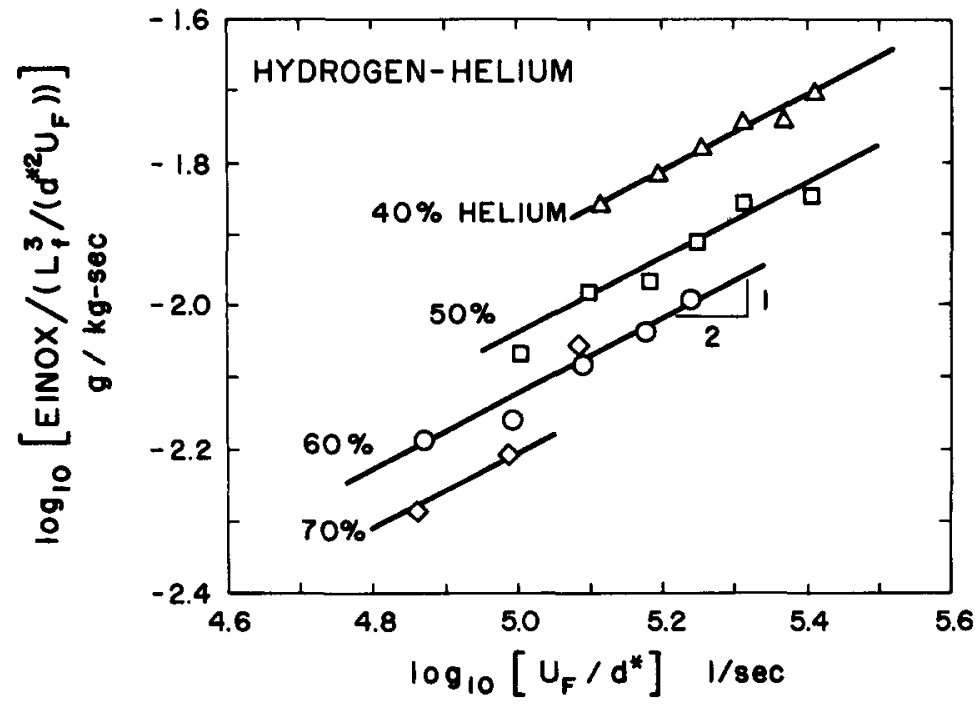

Fig. 6. $\mathrm{NO}_{x}$ emission index normalized using Thring-Newby effective jet diameter $d^{*}$, showing that helium-diluted hydrogen flame data have the same slope of 0.5 as Fig. 3. $d_{F}=0.37 \mathrm{~cm}$. 
Premixed air and coaxial air are important because they are used in low $\mathrm{NO}_{x}$ gas turbines and burners.

Some EINOX measurements are presented in Figs. 7-9 and the premixed case is compared to the coaxial air (nonpremixed) case in Fig. 10. The upper curve in Fig. 7 shows the effect of coaxial air on a hydrogen jet flame; this curve was reported in Ref. 2 and is included for the purpose of comparison. The other curves in Figs. 7 and 8 show the effects of varying fuel type and jet diameter, which were not reported in Ref. 2 . For the nonpremixed coaxial fuel/air geometry, Fig. 7 shows that as the coaxial air velocity is increased, the $\mathrm{NO}_{x}$ emission index decreases to a value that is one-sixth that of the case of no coaxial air (for $d_{F}=0.26 \mathrm{~cm}$ ). Much of this $\mathrm{NO}_{x}$ reduction can be explained by the reduction in flame length. The quantity $\left(L_{f} / L_{f, o}\right)^{3}$ is reduced significantly by the coaxial air, as shown in Fig. 7 and EINOX is predicted by Eq. 1 to be proportional to $\left(L_{f} / L_{f, o}\right)^{3}$. Since reductions in $\mathrm{NO}_{x}$ are shown to be possible if sufficient coaxial air is forced into the jet, it is useful to calculate the conditions that yield the minimum $\mathrm{NO}_{x}$ achievable, which occurs when the flame blows out. Recent theory of Dahm and Mayman [15] accurately predicts the blowout of jet flames with coaxial air, and the minimum flame length at blowout can also be predicted [23]. Swirl is commonly used to extend the flame blowout limits and the improved stability has been quantified in this laboratory by Feikema et al. [24]. As described in Ref. 2, swirl has only a modest effect on $\mathrm{NO}_{x}$ by itself, but it allows the flame to retain stability as coaxial air is forced into the flame, which results in significant $\mathrm{NO}_{x}$ reduction, as shown in Fig. 7.

Figure 8 shows that the addition of coaxial air to the methane-air flame has a different effect than that observed for the hydrogen-air flames. The coaxial air has little effect on the $\mathrm{NO}_{x}$ levels for the larger-diameter methane-air flame $\left(d_{F}=\right.$ $0.37 \mathrm{~cm}$ ) and the coaxial air actually increases $\mathrm{NO}_{x}$ for the smaller flame $\left(d_{F}=0.26 \mathrm{~cm}\right)$. These trends can be explained by the fact that the coaxial air is observed to cause the yellow soot radiation to disappear as the flame is shortened. The $\mathrm{NO}_{x}$ reduction due to reduced flame length is apparently offset by increased flame temperature due to a reduction in the radiant heat loss fraction.

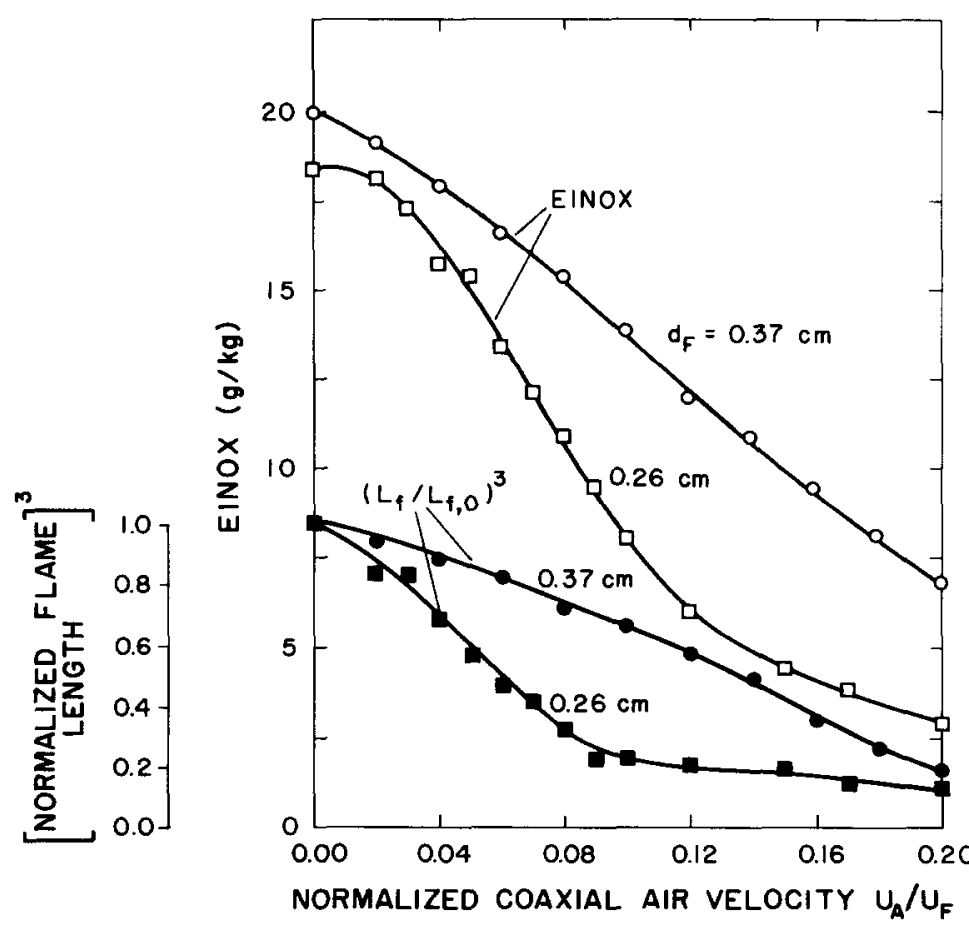

Fig. 7. Reduction in $\mathrm{NO}_{x}$ emission index achievable by adding nonpremixed coaxial air to the jet. Hydrogen fuel; $d_{A}=$ $0.87 \mathrm{~cm}$ 


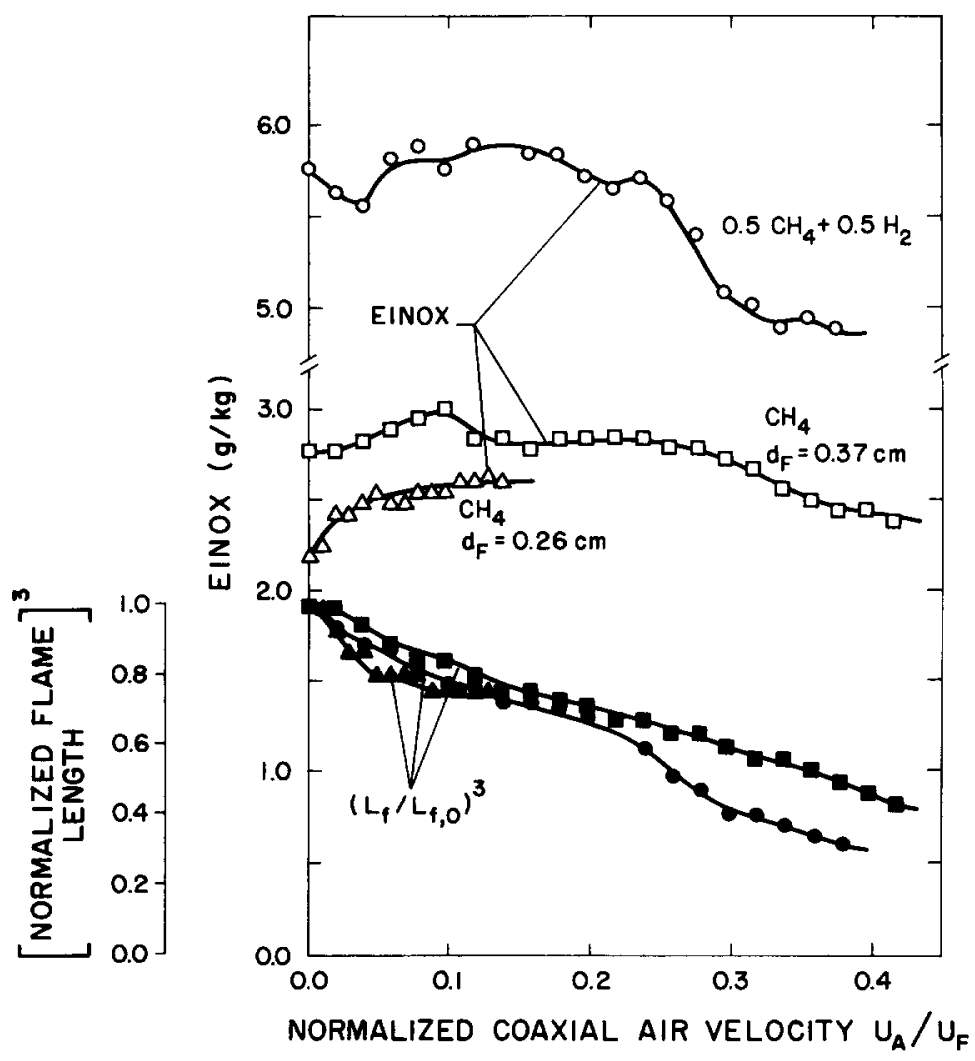

Fig. 8. Effect of coaxial air on $\mathrm{NO}_{x}$ emission index for methane-hydrogen and methane jet flames. $d_{A}=0.87 \mathrm{~cm}$.

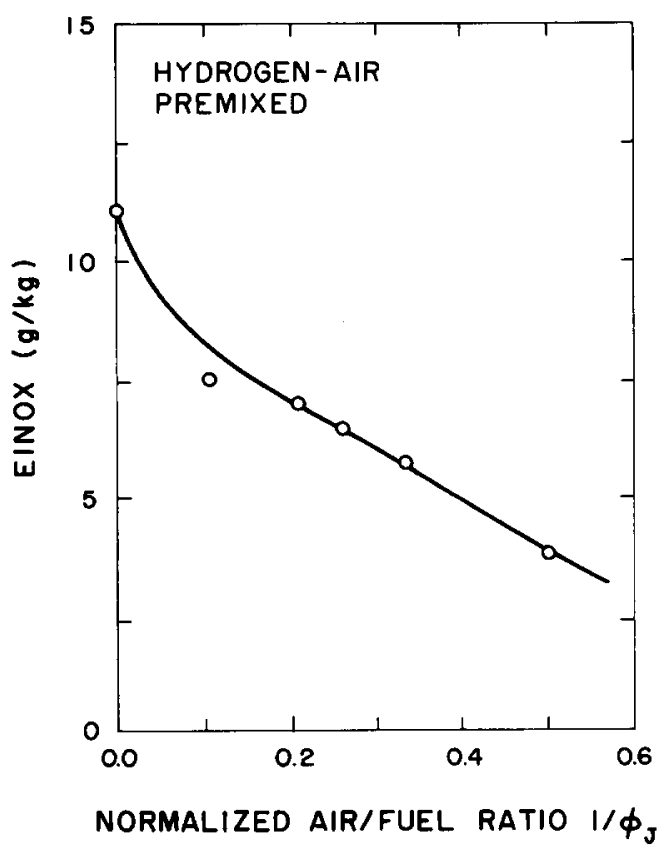

Fig. 9. Reduction in $\mathrm{NO}_{x}$ emission index achievable by adding premixed air to the fuel jet. Hydrogen fuel, $d_{f}=0.26$ $\mathrm{cm}, \operatorname{Re}=5000$, no coaxial air.

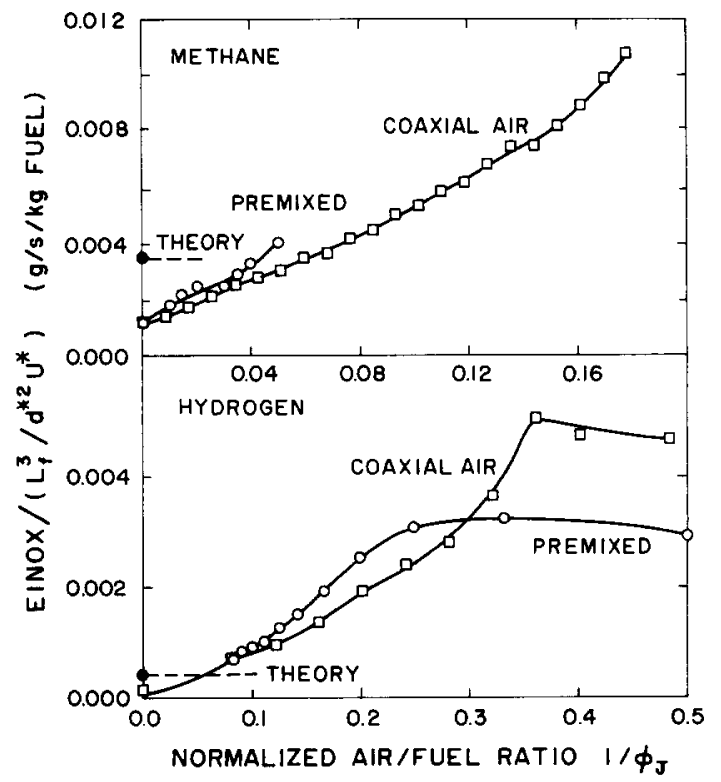

Fig. 10. Comparison of $\mathrm{NO}_{x}$ emission index per unit flame volume for rich premixed flames and nonpremixed coaxial air jet flames. $\operatorname{Re}=5000 ; d_{f}=0.37 \mathrm{~cm}$ for methane flames; $d_{f}=0.26 \mathrm{~cm}$ for hydrogen flames. Theory of Peters shown for pure fuel jet $\left(1 / \phi_{F}=0\right)$. 
$\mathrm{NO}_{x}$ emission index also was reduced when premixed air was added directly to the fuel in the fuel tube. Results in Fig. 9 show that EINOX can be reduced by a factor of three (from 12 to 4 $\mathrm{g} / \mathrm{kg}$ ) by adding premixed air. However, this $\mathrm{NO}_{x}$ reduction is less than that achieved with coaxial air (Fig. 7) because the coaxial air flame is more stable than the premixed air flame and larger quantities of air can be added without causing blowout.

Comparisons of the premixed jet flame data to the coaxial air jet flame data are shown in Figs. 10 and 11 . The equivalence ratio of the jet $\phi_{J}$ is defined as the mass flow of fuel divided by the mass flow of air in the jet (either premixed or coaxial), normalized by the stoichiometric fuel-air mass ratio. It is observed that as more forced air is added to the jet there is an increase in the $\mathrm{NO}_{x}$ emission index per unit flame volume. That is, the flame becomes shorter and louder and the combustion is more intense since the fuel is consumed in a smaller volume than in a long, simple jet flame. The increase in the $\mathrm{NO}_{x}$ emission per unit volume shown in Fig. 10 is believed to be due to the increase in the size of the high-temperature zones resulting from some local premixing of air with the fuel. Thus the forced air increases EINOX per unit volume (Fig. 10) but decreases the total EINOX level of the flame (Figs. 7 and 8). The premixed conditions for the present study are still fuel-rich, so the flame is jetlike and requires entrained air to consume the fuel. The fuel-rich flames are similar to certain low $\mathrm{NO}_{x}$ burner flames that use staged air.

Since flame length is a critical parameter that is used to normalize data in Fig. 10, measured flame lengths for the premixed and coaxial air jets were compared with each other and with theory [15]. Reasonable agreement is shown in Fig. 11 when the flame length is normalized by the effective jet diameter $d^{*}$ as defined in Eq. 1. The Dahm-Mayman analysis [15] shows that $L_{f} / d^{*}$ is $524\left[1+\left(34.4 / \phi_{J}\right)\right]^{-1}$ for hydrogen-air flames and is $269\left[1+\left(17.2 / \phi_{F}\right)\right]^{-1}$ for methane-air flames.

\section{FRACTION OF NO $\mathrm{NHAT}_{x}$ IS $\mathrm{NO}_{2}$}

Previous studies report a large variation in the fraction of $\mathrm{NO}_{x}$ that is $\mathrm{NO}_{2}$ [2-5], which is troublesome for those attempting to assess new

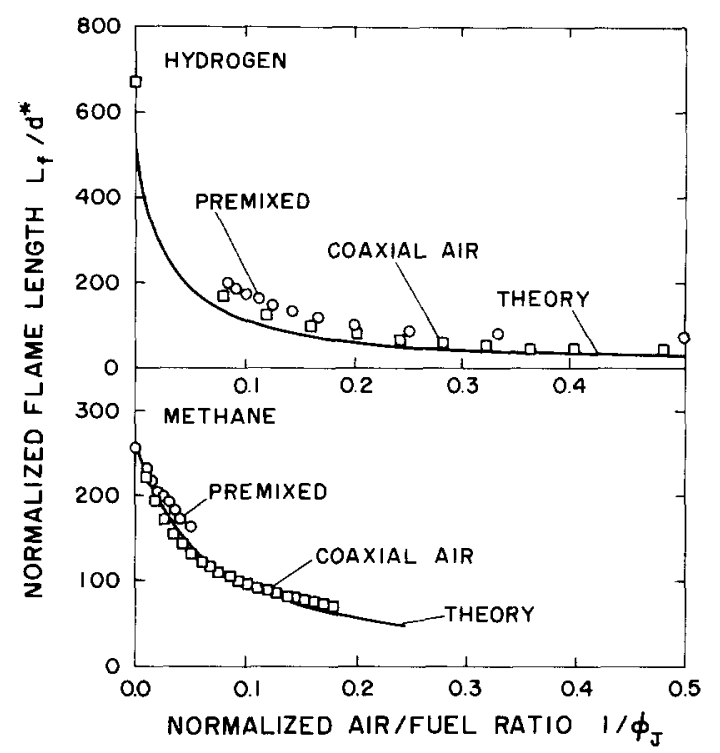

Fig. 11. Comparison of the lengths of rich premixed flames to the lengths of nonpremixed coaxial air jet flames and to the theory of Dahm-Mayman. $d_{F}=0.37 \mathrm{~cm}\left(\mathrm{CH}_{4}\right), d_{f}=0.26$ $\mathrm{cm}\left(\mathrm{H}_{2}\right), d_{A}=0.87 \mathrm{~cm}$.

$\mathrm{NO}_{x}$ models. The present results indicate that once NO is formed just downstream of the flame, the fraction of the NO that is converted into $\mathrm{NO}_{2}$ is extremely sensitive to fluid mechanical mixing of air into the jet. Figure 12 shows that the small coflow air velocities $\left(U_{\infty}\right)$ of the present work do not affect the total EINOX values for the values of $U_{\infty} / U_{F}$ used which are always less than 0.03 . Thus the present flame is believed to be identical to an unconfined jet flame with no coflow air when assessing the EINOX data of Figs. 2-10. However, Fig. 12 shows that the coflow air velocity has a large effect on the fraction of NO that is converted to $\mathrm{NO}_{2}$ downstream of the flame tip. The percentage of $\mathrm{NO}_{x}$ that is $\mathrm{NO}_{2}$ varies from $8 \%$ to $80 \%$ as coflow air velocity $\left(U_{\infty} / U_{F}\right)$ increases up to 0.03 . Note that coflow air differs from coaxial air as shown in Fig. 1; the results in Fig. 12 were obtained for jet flames with no coaxial air.

One reason that the coflow air does not affect the total $\mathrm{NO}_{x}$ levels in Fig. 12 but is found to affect the conversion of $\mathrm{NO}$ to $\mathrm{NO}_{2}$ is now offered. Consider two regions: the first $(0<z<$ $1.5 L_{f}$ ) is the NO formation region because EINOX levels are shown to be constant at locations downstream of 1.5 flame lengths [2]. The second is the NO-to- $\mathrm{NO}_{2}$ conversion region which 


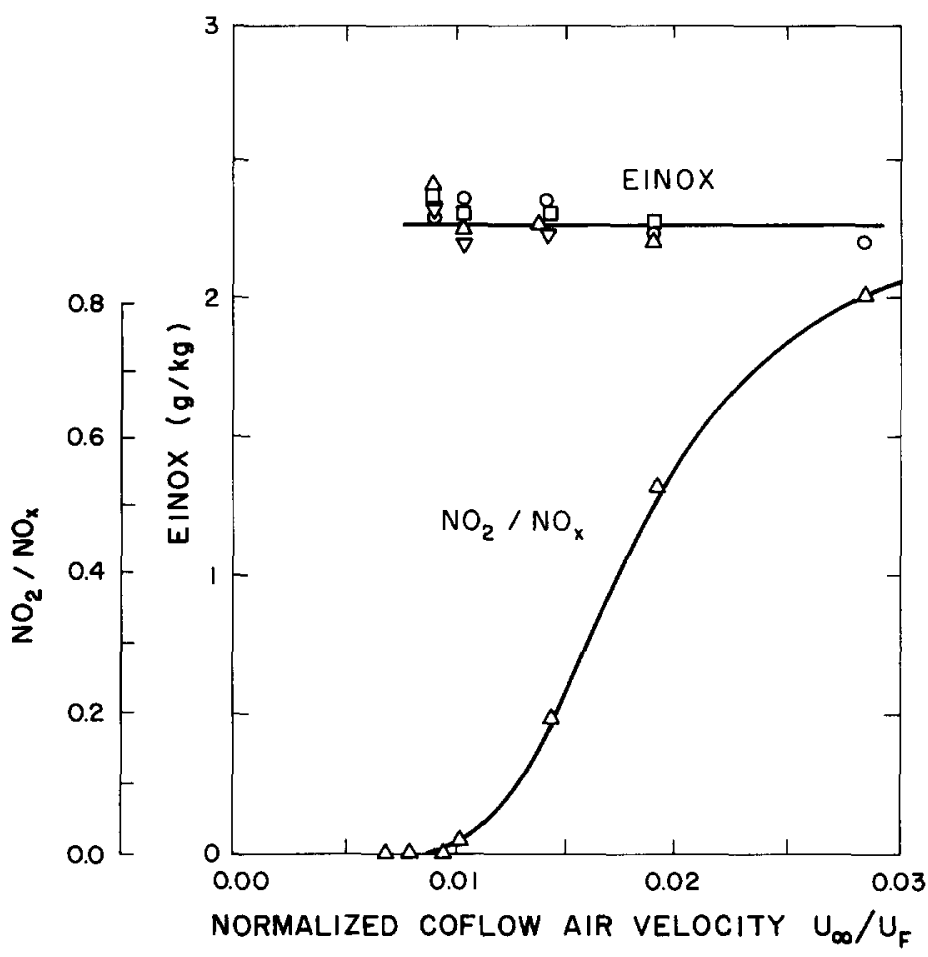

Fig. 12. Effect of coflow air velocity $\left(U_{\infty}\right)$ on total $\mathrm{NO}_{x}$ emission index and on the fraction of $\mathrm{NO}_{x}$ that is $\mathrm{NO}_{2}$. Methane jet flame, no coaxial air, $d_{F}=0.37 \mathrm{~cm}$; $\operatorname{Re}_{F}$ $=0,5000 ; \square, 6000 ; \triangle, 7000 ; \nabla, 8000$. is downstream of $1.5 L_{f}$ and occurs between the temperature contours associated with 700 and 900 $\mathrm{K}$. This is the temperature range that is known to favor $\mathrm{NO}$ conversion to $\mathrm{NO}_{2}$ due to the presence of $\mathrm{HO}_{2}$ [25]. It is argued that the coflow air velocity $\left(U_{\infty}\right)$ has little effect in the first region and therefore does not affect total EINOX levels because $U_{\infty}$ is less than $3 \%$ of the jet exit velocity. However, the coflow air velocity does have an effect on the second region since downstream of $1.5 L_{f}$ the jet centerline velocity has decreased to less than $1 \%$ of the jet exit velocity and is comparable to the coflow air velocity. Thus even relatively low-velocity coflow air affects the mixing in the downstream $\mathrm{NO}-\mathrm{NO}_{2}$ conversion region. The physical reason that enhanced mixing can promote $\mathrm{NO}_{2}$ conversion is only partially understood but is documented in other studies [25].

\section{CONCLUSION}

1. Values of $\mathrm{NO}_{x}$ emission index for hydrogen/ helium-air jet flames as well as undiluted hydrogen-air jet flames are found to be correlated by lines having a slope of 0.5 when the data are normalized by the global residence time and are plotted using the independent variable $U_{F} / d_{F}$. This implies that Reynolds number, which has been used previously, is not the governing physical parameter. $U_{F} / d_{F}$ can be interpreted as an indicator of the Damkohler number, which indicates that $\mathrm{NO}_{x}$ models need to include the effects of strain and nonequilibrium chemistry.

2. The $\mathrm{NO}_{x}$ levels of all the hydrogen, methane, and propane flames studied were found to be less than (or equal to) the thermal theory predictions when no inert diluents were used. The reason for this difference cannot be explained by prompt $\mathrm{NO}_{x}$ or superequilibrium oxygen since such mechanisms would cause measured $\mathrm{NO}_{x}$ to exceed predicted thermal $\mathrm{NO}_{x}$ which is not observed. The low measured $\mathrm{NO}_{x}$ values instead are believed to be due to strain and/or radiant heat losses that tend to reduce $\mathrm{NO}_{x}$ levels.

3. Adding inerts to the jet decreased the $\mathrm{NO}_{x}$ emission index, but the decrease is not as large as that predicted by the equilibrium theory of Peters and Donnerhack [1]. The deviation from equilibrium was varied so that the 
$\mathrm{NO}_{x}$ measurements can be used to assess complex chemistry models.

4. Premixed or coaxial air considerably shortens the jet flames and reduces the residence time and $\mathrm{NO}_{x}$ emission index by as much as a factor of 6. Eventually, however, excessive amounts of air added to the jet increase the $\mathrm{NO}_{x}$ produced per unit flame volume, which would be expected when local premixing or homogenization occurs. The $\mathrm{NO}_{x}$ reduction due to coaxial air added to methane-air flames is less than that for hydrogen-air flames due to the competing effects of flame radiation.

This research is supported by the Gas Research Institute under contract 5087-260-1443; the contract monitors have been $T$. Roose and J. Kezerle. The authors acknowledge useful discussions with S. R. Turns and W. J. A. Dahm.

\section{REFERENCES}

1. Peters, N., and Donnerhack, S., Eighteenth Symposium (International) on Combustion, The Combustion Institute, Pittsburgh, 1981, p. 22.

2. Chen, R.-H., and Driscoll, J. F., Twenty-Third Symposium (International) on Combustion, The Combustion Institute, Pittsburgh, 1991, p. 281.

3. Turns, S. R., and Lovett, J. A., Combust. Sci. Technol. 66: 233-249 (1989).

4. Turns, S. R., and Myhr, F. H., Combust. Flame, in press.

5. Drake, M. C., Correa, S. M., Pitz, R. W., Shyy, W., and Fenimore, C. P., Combust. Flame 69: 347-365 (1987).

6. Kent, J. H., and Bilger, R. W., Sixteenth Symposium (International) on Combustion, The Combustion Institute, Pittsburgh, 1977, p. 1643.

7. Drake, M. C., and Blint, R. J., Combust. Flame 83:185-203 (1991).
8. Janicka, J., and Kollman, W., Seventeenth Symposium (International) on Combustion, The Combustion Institute, Pittsburgh, 1978, p. 421.

9. Drake, M. C., and Blint, R. J., Combust. Sci. Technol. 61:187-224 (1988).

10. Chen, J. Y., and Kollmann, W., Combust. Flame, in press.

11. Hayhurst, A. N., and Vince, I. M., Prog. Ener. Combust. Sci. 6:35-51 (1980).

12. Lutz, A. E., Kee, R. J., Dibble, R. W., and Broadwell, J. E., AIAA Paper 91-0478, 1991.

13. Dahm, W. J. A., Tryggvason, G., and Krasny, R., GRI Annual Report 5088-260-1692, 1990.

14. Thring, M. W., and Newby, M. P., Fourth Symposium (International) on Combustion, The Combustion Institute, Pittsburgh, 1952, p. 789.

15. Dahm, W. J. A., and Mayman, A. G., $A I A A$ J. 28, 1157-1162 (1990).

16. Carrier, G. F., Fendell, F. E., and Marble, F. E., SIAM J. Appl. Math. 28:463-500 (1975).

17. Bilger, R. W., Twenty-Second Symposium (International) on Combustion, The Combustion Institute, Pittsburgh, 1988, p. 475.

18. Shaw, H., Trans. ASME, July, 1974, p. 240.

19. Markstein, G. G., Sixteenth Symposium (International) on Combustion, The Combustion Institute, Pittsburgh, 1976, p. 1407.

20. Becker, H. A., and Liang, D., Combust. Flame 32:115-137 (1978).

21. Hawthorne, W. R., Weddell, D. S., and Hottel, H., Third Symposium (International) on Combustion, The Combustion Institute, Pittsburgh, 1948, p. 266.

22. Gore, J. P., Jeng, S.-M., and Faeth, G. M., ASME J. Heat Transf. 109:165-171 (1987).

23. Feikema, D., Chen, R.-H., and Driscoll, J. F., Combust. Flame, 86:347-358 (1991).

24. Feikema, D., Chen, R.-H., and Driscoll, J. F., Combust. Flame 80:183-195 (1990).

25. Hori, M., Twenty-First Symposium (International) on Combustion, The Combustion Institute, Pittsburgh, 1986, p. 1181.

Received 10 June 1991; revised 3 September 1991 